\title{
ESTÁDIO DE MATURAÇÃO E QUALIDADE DE SEMENTES APÓS REPOUSO DE FRUTOS DE MARACUJÁ AMARELO ${ }^{1}$
}

\author{
ERNEIDACOELHODE ARAÚJO², ROBERTOFERREIRADA SILVA ${ }^{3}$, ALEXANDREPIO VIANA ${ }^{3}$, MARCOS VINÍCIUS DA SILVA ${ }^{4}$
}

\begin{abstract}
RESUMO - Investigações sobre o efeito do repouso de frutos na qualidade das sementes evidenciam que há uma relação direta entre este repouso e o aumento da germinação e vigor das sementes avaliadas. O objetivo deste estudo foi avaliar a influência do estádio de maturação e do armazenamento de frutos na qualidade fisiológica de sementes de maracujá amarelo. Os frutos foram obtidos a partir de polinização manual, sendo que a colheita dos frutos foi realizada em três estádios de maturação: 55, 60 e 65 dias após a antese e armazenados às temperaturas de $8{ }^{\circ} \mathrm{C}$ e $25^{\circ} \mathrm{C}$, por 7,14 e 21 dias de repouso. Para avaliação da qualidade das sementes, as características utilizadas foram: teor de água, massa seca das sementes, germinação e vigor. As sementes de maracujá amarelo provenientes dos frutos com 65 dias de idade e submetidos ao repouso por sete dias, tanto em ambiente refrigerado quanto natural, tem maior qualidade fisiológica; frutos colhidos aos 65 dias de idade após a antese e armazenados por sete dias às temperaturas de $8^{\circ} \mathrm{C}$ e $25^{\circ} \mathrm{C}$ apresenta também maior acúmulo de matéria seca.
\end{abstract}

Termos para indexação: Passiflora, armazenamento, germinação, vigor.

\section{DEGREE OF MATURATION AND STORAGE ON SEED QUALITY OF PASSIONFRUITS}

\begin{abstract}
Investigation on the effect of rest of fruits on seed quality has shown a direct relationship between rest and increase in the seed germination and vigor. The objective of this study was to evaluate the influence of the degree of maturation and fruit rest on the physiological quality of passion fruit seeds. The fruits were obtained by hand pollination, and the fruits were harvested at three maturation stages: 55, 65 and 75 days after anthesis and stored at $25^{\circ}$ and $8^{\circ} \mathrm{C}$ for 7,14 and 21 days of rest. To evaluate the seed quality, the following characteristics were assessed: mixture content, seed dry matter, germination and vigor. Seeds from 65-day-old fruits and submitted to rest for 7 days, kept in a cooled environment and at room temperature showed better physiological quality; 65 -day-old fruits harvested at anthesis and stored fo seven days at $8^{\circ} \mathrm{C}$ and $25^{\circ} \mathrm{C}$ presented also the largest accumulation of dry matter.
\end{abstract}

Index terms: Passiflora, seeds, germination, vigor

1 Submetido em 16/11/2006. Aceito para publicação em 18/04/2007. Parte da Tese de Doutorado do primeiro autor.

2 Professora Substituta, Departamento de Oceanografia - UFPA, Universidade Federal do Pará, Belém, PA, 66075-110.erneida@ufpa.br.

3 Professor Titular da UENF, Universidade Estadual do Norte Fluminense Darcy Ribeiro - UENF/CCTA /LFIT. Campos dos Goytacazes-RJ. roberto@uenf.br

4 Estudante de Agronomia da UENF, Universidade Estadual do Norte Fluminense Darcy Ribeiro. 


\section{INTRODUÇÃO}

A utilização ou não do repouso de frutos, bem como o tempo de sua duração, definirá duas ou três épocas diferentes de colheita, principalmente quando se visa obter a máxima qualidade das sementes. Via de regra, quanto maior o período de repouso dos frutos, mais precoce poderá ser a colheita. Esta afirmação é válida para cultivares de pepino (Barbedo et al., 1994) e pimentão (Mantovani et al., 1980). Da mesma forma, além da eventual necessidade de antecipar-se a colheita, o nível de qualidade que se deseja das sementes condicionará o tempo mínimo necessário de repouso dos frutos. No trabalho com sementes de pimentão, o repouso pós-colheita dos frutos resultou em sementes com capacidade germinativa em idades, em que normalmente sem o repouso do fruto, a germinação da semente seria nula (Mantovani et al., 1980).

Em frutos climatéricos como mamão, quando o tecido vegetal atinge a maturidade fisiológica, a taxa respiratória, bem como a emissão de etileno, aumentam até atingirem um máximo, seguindo-se decréscimo (Kays, 1997). O etileno pode agir inibindo ou promovendo a germinação das sementes. Nas espécies em que a germinação é estimulada pelo etileno, o mecanismo, aparentemente, está envolvido na regulação de níveis de auxina em sementes dormentes (Copeland e Mc Donald, 1985). Sementes dormentes têm baixa capacidade de produzir etileno em relação às sementes colhidas sem dormência (Murray,1984).

Estudando a influência da época de colheita e do repouso dos frutos de mamão na qualidade fisiológica das sementes, Aroucha (2004) concluiu que a época de colheita do fruto e o período de repouso contribuíram para um aumento significativo na germinação das sementes, independentemente da época de colheita do fruto. A autora afirma ainda que o vigor das sementes parece estar associado às mudanças na fisiologia dos frutos de mamão durante o armazenamento, já que a permanência das sementes no seu interior, durante o pico climatérico, melhorou a qualidade das sementes.

Com o objetivo de estudar a influência da emissão de etileno na qualidade fisiológica de sementes de mamão (Carica papaya) do grupo solo (cv. Golden), durante o período de armazenamento dos frutos em presença e ausência de um adsorvedor de etileno (permanganato de potássio - $\mathrm{KMnO}_{4}$ ), Silva, et. al. (2004) concluíram que a presença do permanganato de potássio propiciou expressiva redução (50\%) na emissão de etileno; e que o armazenamento dos frutos de mamão, a $25^{\circ} \mathrm{C}$ por oito dias, proporcionou um aumento significativo na qualidade de sementes; a máxima qualidade das sementes foi obtida a partir do $4^{\circ}$ dia de armazenamento, após os frutos terem atingido o pico climatérico.

Ao avaliar o efeito da maturidade do fruto e do seu repouso pós-colheita na germinação de sementes de maracujá doce (Passiflora alata Dryander) em ambiente natural e refrigerador, utilizando frutos em ponto de colheita comercial (início de mudança da coloração verde para amarela, no ápice do fruto) e frutos amadurecidos na planta, próximos ao seu desprendimento, Osipi (2000) verificou que os frutos amadurecidos na planta e submetidos ao repouso em ambiente natural, tanto aqueles maduros quanto no ponto de colheita, propiciaram sementes com melhor qualidade fisiológica.

$\mathrm{Na}$ propagação é essencial que as sementes do maracujazeiro sejam coletadas de frutos completamente maduros (Ruggiero , 1987). Em se tratando de maracujá amarelo, o qual também é um fruto climatérico, poucos estudos têm sido realizados e em razão da escassez de informações, este trabalho foi desenvolvido com o objetivo de avaliar o efeito do estádio de maturação e do repouso de frutos na qualidade fisiológica de sementes de maracujá.

\section{MATERIAL E MÉTODOS}

O experimento foi instalado numa lavoura situada no município de Campos dos Goytacazes - RJ, no período de março a maio de 2004. O solo do tipo argissol amarelo, desenvolvido a partir de sedimentos terciários, horizonte $\mathrm{B}$ textural com camada superficial arenosa, e relevo suavemente ondulado que caracterizam as condições edáficas e climáticas (Quadro 1) dos locais onde geralmente se cultiva esta fruteira na região Norte Fluminense (Carvalho et al., 2000).

Os frutos, oriundos de uma mistura de dois grupos de plantas, as seleções conhecidas como: Maguari e Yellow Master, foram obtidos por polinização manual, feita do seguinte modo: com os dedos tocava-se nas anteras da flor 
até que ficassem os mesmos impregnados pelo pólen, em seguida, tocava-se levemente nos três estigmas de uma flor de outra planta.

Frutos em três estádios de maturação 55, 60 e 65 dias após a antese (DAA) foram armazenados às temperaturas de $8^{\circ} \mathrm{C}$ e $25^{\circ} \mathrm{C}$ por sete, 14 e 21 dias. Após cada período de repouso, as sementes foram extraídas. Removeu-se a mucilagem presente nas sementes, utilizando-se um despolpador. A secagem das sementes foi realizada em ambiente natural à sombra. $\mathrm{O}$ arilo foi totalmente removido, friccionando as sementes contra a tela da peneira de arame. Foram utilizados vinte e um tratamentos (Tabela 3).

Para avaliar a maturação fisiológica e qualidade das sementes, determinações e testes foram realizados no Setor de Produção e Tecnologia de Sementes do Laboratório de Fitotecnia da Universidade Estadual do Norte Fluminense Darcy Ribeiro, no período de dezembro à maio de 2005. O teor de água - determinado pelo método da estufa, regulada a $105^{\circ} \pm 3^{\circ} \mathrm{C}$, durante 24 horas (Brasil, 1992), utilizando-se duas amostras de três gramas de sementes; massa seca das sementes - utilizou-se quatro subamostras de 10 sementes, em estufa com ventilação forçada, a $75^{\circ} \mathrm{C}$, até peso constante; teste de germinação - foram utilizadas quatro subamostras de 25 sementes, as quais foram retiradas dos tratamentos correspondentes e colocadas entre três camadas de papel toalha, germiteste, e a quantidade de água acrescentada foi igual à massa do papel seco multiplicado por 2,5 e em seguida transferidas para uma câmara de germinação do tipo BOD, sob a temperatura de $20-30^{\circ} \mathrm{C}, 16$ horas de escuro e 8 horas de luz, condições indicadas para a espécie, conforme as Regras para Análise de Sementes (Brasil, 1992). As avaliações foram realizadas aos 14 dias (primeira contagem) e aos 28 dias (contagem final), sendo os resultados expressos em percentagem de plântulas normais; envelhecimento acelerado - para cada tratamento, quatro repetições de 100 sementes foram distribuídas uniformemente, sobre telas de arame e colocadas no interior de caixas plásticas com tampa gerbox contendo, ao fundo, $40 \mathrm{ml}$ de água destilada. As caixas foram postas transferidas para uma câmara $\mathrm{BOD}$, à temperatura de $42{ }^{\circ} \mathrm{C}$, onde permaneceram por um período de 72 horas. Após este período, 25 sementes de cada repetição foram retiradas e colocadas para germinar seguindo os procedimentos do teste de germinação; condutividade elétrica - foi efetuado por meio de subamostras de 25 sementes, por repetição, totalizando 100 sementes, por tratamento. As subamostras foram pesadas e colocadas em copos plásticos com capacidade para $200 \mathrm{ml}$, contendo cada copo $75 \mathrm{ml}$ de água destilada, em seguida, acondicionados, por 24 horas, em uma câmara de germinação, a temperatura de $25^{\circ} \mathrm{C}$. Após este período, procedeu-se à leitura da condutividade elétrica das soluções contendo os lixiviados das sementes, em condutivímetro Marconi, modelo CA-150, previamente calibrado, sendo os resultados expressos em $\mathrm{mS} \cdot \mathrm{cm}^{-1} \cdot \mathrm{g}^{-1}$.

\section{Procedimentos estatísticos}

Os tratamentos foram submetidos à análise de variância no modelo inteiramente casualizado, com quatro repetições, sendo os tratamentos dispostos no arranjo fatorial $3 \times 3 \times 2$, correspondentes a três idades do fruto (55, 60 e 65 dias após antese), três períodos de aramazenamento (7, 14 e 21 dias), duas temperaturas de armazenamentos dos frutos $\left(8^{\circ} \mathrm{Ce} 25^{\circ} \mathrm{C}\right)$.

\section{RESULTADOS E DISCUSSÃO}

Os resultados das avaliações da qualidade das sementes utilizadas neste experimento estão apresentadas nas Tabelas 1 e 2 respectivamente.

O decréscimo do teor de água das sementes ocorreu aos 55 e 60 DAA, em frutos armazenados a $25^{\circ} \mathrm{C}$, até 21 dias . Em frutos com 65 dias de idade, armazenados por 21 dias a $25^{\circ} \mathrm{C}$, houve acréscimo no teor de água, no entanto nos frutos armazenados a $8^{\circ} \mathrm{C}$, verificou-se uma redução no teor de água aos 7 dias (Tabela 1).

Estudando a influência da idade e do período de repouso pós-colheita de frutos de pepino na qualidade de sementes, Barbedo et al. (1994) verificaram que a umidade das sementes de frutos sem repouso pós-colheita decresceu desde as primeiras idades estudadas até os 40 dias, quando alcançaram aproximadamente $40 \%$. Com o repouso dos frutos, a umidade das sementes decresceu em sementes provenientes de frutos mais novos. Porém, com o avanço da idade este decréscimo mostrou-se menos evidente até que, nas últimas idades, a partir de aproximadamente 35 dias, não houve mais decréscimo da umidade das sementes em função do armazenamento dos frutos. 


\begin{tabular}{l|c|c|c|c}
\hline \multicolumn{1}{c|}{ Mês/ano } & $\begin{array}{c}\text { Tmédia } \\
\left({ }^{\circ} \mathrm{C}\right)\end{array}$ & $\begin{array}{c}\text { Tmáxima } \\
\left({ }^{\circ} \mathrm{C}\right)\end{array}$ & $\begin{array}{c}\text { Tmínima } \\
\left({ }^{\circ} \mathrm{C}\right)\end{array}$ & $\begin{array}{c}\text { PP } \\
(\mathrm{mm})\end{array}$ \\
\hline Jan/03 & 26,0 & 32,4 & 22,3 & 226,8 \\
\hline Fev/03 & 26,9 & 33,7 & 21,8 & 15,5 \\
\hline Mar/03 & 26,2 & 33,1 & 21,9 & 153,3 \\
\hline Abr/03 & 24,4 & 30,6 & 20,3 & 82,1 \\
\hline Mai/03 & 218 & 27,6 & 17,4 & 88,4 \\
\hline Jun/03 & 21,7 & 28,9 & 16,9 & 0,4 \\
\hline Jul/03 & 20,3 & 26,8 & 15,5 & 35,2 \\
\hline Ago/03 & 19,9 & 25,4 & 15,7 & 50,3 \\
\hline Set/03 & 22,8 & 37,4 & 18,5 & 39,3 \\
\hline Out/03 & 24,0 & 28,7 & 19,5 & 66,9 \\
\hline Nov/03 & 26,0 & 30,7 & 21,4 & 65,9 \\
\hline Dez/03 & 25,0 & 30,7 & 21,5 & 135,8 \\
\hline Jan/04 & 24,5 & 29,3 & 21,1 & 146,0 \\
\hline Fev/04 & 24,9 & 30,4 & 21,2 & 90,4 \\
\hline Mar/04 & 24,5 & 30,6 & 20,3 & 12,3 \\
\hline Abr/04 & 23,9 & 30,2 & 20,2 & 99,8 \\
\hline Mai/04 & 25,2 & 30,4 & 21,8 & 7,22 \\
\hline
\end{tabular}

QUADRO 1 - Media de temperatura (máxima, média e mínima) e precipitação total (PP), observadas na Estação experimental da Pesagro, em Campos dos Goytacazes, de janeiro de 2003 a maio de 2004.

Fonte: Estação Meteorológica da Pesagro - Laboratório de Engenharia Agrícola do Centro de Ciências e Tecnologias Agropecuárias da Universidade Estadual do Norte Fluminense.

TABELA 1. Valores médios referentes ao teor de água (U) e massa seca (MS) de sementes de maracujá amarelo em função da idade dos frutos (DAA), período de armazenamento - PA (dias) e temperatura ambiente de armazenamento $\left({ }^{\circ} \mathrm{C}\right)$.

\begin{tabular}{lccccc}
\hline \multirow{2}{*}{$\begin{array}{c}\text { Idade dos frutos (DAA) } \\
\text { (após a antese) DAA }\end{array}$} & PA (dias) & \multicolumn{2}{c}{ Teor de água (\%) } & \multicolumn{2}{c}{ Massa seca $(\mathrm{g})$} \\
\cline { 3 - 6 } & & \multicolumn{3}{c}{ Temperatura $\left({ }^{\circ} \mathrm{C}\right)$} \\
\cline { 3 - 6 } & 7 & $27,0 \mathrm{bA}$ & $33,3 \mathrm{aB}$ & $0,92 \mathrm{aA}$ & $0,79 \mathrm{bA}$ \\
& 14 & $26,9 \mathrm{bA}$ & $32,2 \mathrm{aB}$ & $0,77 \mathrm{aA}$ & $1,09 \mathrm{aB}$ \\
& 21 & $31,7 \mathrm{aA}$ & $22,6 \mathrm{bB}$ & $0,87 \mathrm{aA}$ & $1,22 \mathrm{aB}$ \\
\hline 65 & 7 & $29,5 \mathrm{aA}$ & $43,4 \mathrm{aB}$ & $1,00 \mathrm{aA}$ & $0,75 \mathrm{bB}$ \\
& 14 & $21,2 \mathrm{bA}$ & $44,4 \mathrm{aB}$ & $0,98 \mathrm{aA}$ & $0,71 \mathrm{bB}$ \\
& 21 & $27,2 \mathrm{aA}$ & $26,2 \mathrm{bA}$ & $0,91 \mathrm{aA}$ & $1,02 \mathrm{aA}$ \\
\hline 65 & 7 & $22,2 \mathrm{bA}$ & $21,7 \mathrm{bA}$ & $0,93 \mathrm{a} \mathrm{A}$ & $0,92 \mathrm{aA}$ \\
& 14 & $31,2 \mathrm{aA}$ & $22,2 \mathrm{bB}$ & $0,7 \mathrm{bA}$ & $1,01 \mathrm{aB}$ \\
& 21 & $22,2 \mathrm{bA}$ & $33,5 \mathrm{aB}$ & $0,84 \mathrm{aA}$ & $0,87 \mathrm{aA}$ \\
\hline
\end{tabular}

Na coluna, médias seguidas de letras minúsculas iguais não diferem pelo teste de Tukey ao nível de 5\% de probabilidade.

Na linha, médias seguidas de letras maiúsculas iguais não diferem pelo teste de Tukey ao nível de 5\% de probabilidade. 
O descréscimo de umidade das sementes foi observado também por Wuthipongprasert et al. (1985), até 40 dias de idade em abóbora e por Barbedo et al. (1993), até os 50 dias de idade em frutos de pepino.

Verificou-se aumento significativo na massa seca das sementes provenientes de frutos com 55 dias de idade, após 14 e 21 dias de repouso (Tabela 1), nas sementes extraídas de frutos armazenados a $25^{\circ} \mathrm{C}$. Nos frutos com 65 dias, a massa seca das sementes extraídas de frutos mantidos a $25^{\circ} \mathrm{C}$ permaneceu elevada, embora não diferisse da massa seca das sementes retiradas de frutos armazenados a $8^{\circ} \mathrm{C}$, exceto aos 14 dias de armazenamento onde a massa seca das sementes foi inferior na temperatura de $8^{\circ} \mathrm{C}$ (Tabela 2).

Observou-se um acréscimo na massa seca da semente proveniente de frutos colhidos com 55 e 60 dias após a antese nos frutos armazenados por $7 \mathrm{e} 14$ dias, quando foram armazenados à temperatura de $25^{\circ} \mathrm{C}$. Segundo Araújo et al. (1982), esse efeito significativo na massa seca da semente, após o período de armazenamento, indica continuação do fluxo de nutrientes do fruto para a semente mesmo após a colheita. A massa seca é considerada por diversos autores, uma das medidas mais seguras da maturidade da semente. A semente alcança sua maturidade fisiológica quando atinge a massa seca máxima.

Ao avaliar a influência da idade do fruto na qualidade de sementes de pepino, Barbedo et al. (1993) verificaram que o conteúdo de matéria seca das sementes apresentouse crescente com o avanço da idade dos frutos e, praticamente, estabilizou-se a partir dos 35 dias após a antese. Wuthipongprasert et al. (1985), Saadiah e Junaidah (1986) e Barbedo et al. (1993) observaram aumento no conteúdo de matéria seca das sementes, respectivamente, até os 40, 33 e 43 dias de idade dos frutos. Wuthipongprasert et al. (1985) obtiveram ainda, aumento nos valores desta característica com o repouso dos frutos de abóbora, principalmente em sementes de frutos mais novos.

O aumento do conteúdo de matéria seca da semente, observado no período de armazenamento dos frutos de abóbora, segundo Araújo et al. (1982) foi menor que o obtido quando os frutos permanecem ligados à planta durante $o$ mesmo período. Os autores verificaram que a massa seca das sementes de frutos colhidos com 25 dias de idade $(6,02$ $\mathrm{mg}$ ) foi maior que o das retiradas de frutos colhidos com quinze dias e armazenados durante duas semanas $(4,49 \mathrm{mg})$.
Além disso, essas mesmas sementes atingiram massa seca $(6,56 \mathrm{mg})$ semelhante ao das sementes de frutos com 25 dias de idade $(6,02 \mathrm{mg})$, somente após cinco semanas de armazenamento dos frutos.

Resultados divergentes foram encontrados por Osipi (2000) que ao avaliar o efeito da temperatura, da maturação do fruto e do armazenamento na qualidade fisiológica de sementes de maracujá doce, observou que tanto o amadurecimento do fruto ainda ligado à planta, como em repouso pós-colheita, possibilitou um maior acúmulo de matéria seca nas sementes.

Observa-se na Tabela 2 que para as três idades do fruto não houve diferença significativa na germinação da semente em função da temperatura de armazenamento do fruto, exceto aos 55 DAA, após 14 dias de repouso do fruto, onde se observou diferença significativa. Aos 65 DAA, verificouse a maior média de germinação após sete dias de armazenamento do fruto sob temperatura de $25^{\circ} \mathrm{C}$. É importante destacar que aos 65 DAA observou-se um crescimento na massa seca nas sementes retiradas de frutos armazenados a $25^{\circ} \mathrm{C}$, por 14 dias.

Resultados semelhantes foram encontrados por Osipi (2000) ao avaliar o efeito da maturidade do fruto e do seu repouso pós-colheita na germinação de sementes de maracujá doce (Passiflora alata Dryander) em condições de ambiente natural e de refrigerador, utilizando frutos em ponto de colheita comercial e frutos amadurecidos na planta, próximos a sua queda. O referido pesquisador verificou que os frutos amadurecidos na planta e submetidos ao repouso em ambiente natural, tanto aqueles maduros quanto em ponto de colheita, propiciaram sementes com melhor qualidade fisiológica.

Além disso, Osipi (2000) observou que para o fruto de maracujá doce em ponto de colheita comercial, o repouso pós-colheita do fruto por 21 dias, promoveu aumento da porcentagem de plântulas normais, atingindo valores semelhantes aos mesmos tratamentos para o fruto próximos a sua queda e durante o repouso ocorreu o amadurecimento do fruto em ponto de colheita comercial, o que deve ter favorecido a maturação das sementes. Neste mesmo estudo o autor verificou ainda que para algumas variáveis, como: matéria seca, peso de 100 sementes, percentagem de germinação, percentagem e velocidade de emergência, os frutos em ponto de colheita comercial e frutos maduros, 
TABELA 2. Valores médios referentes à germinação (G), envelhecimento acelerado (EA) e condutividade elétrica (CE) de sementes de maracujá amarelo em função da idade dos frutos (DAA), período de armazenamento - PA (dias) e temperatura ambiente de armazenamento $\left({ }^{\circ} \mathrm{C}\right.$ ).

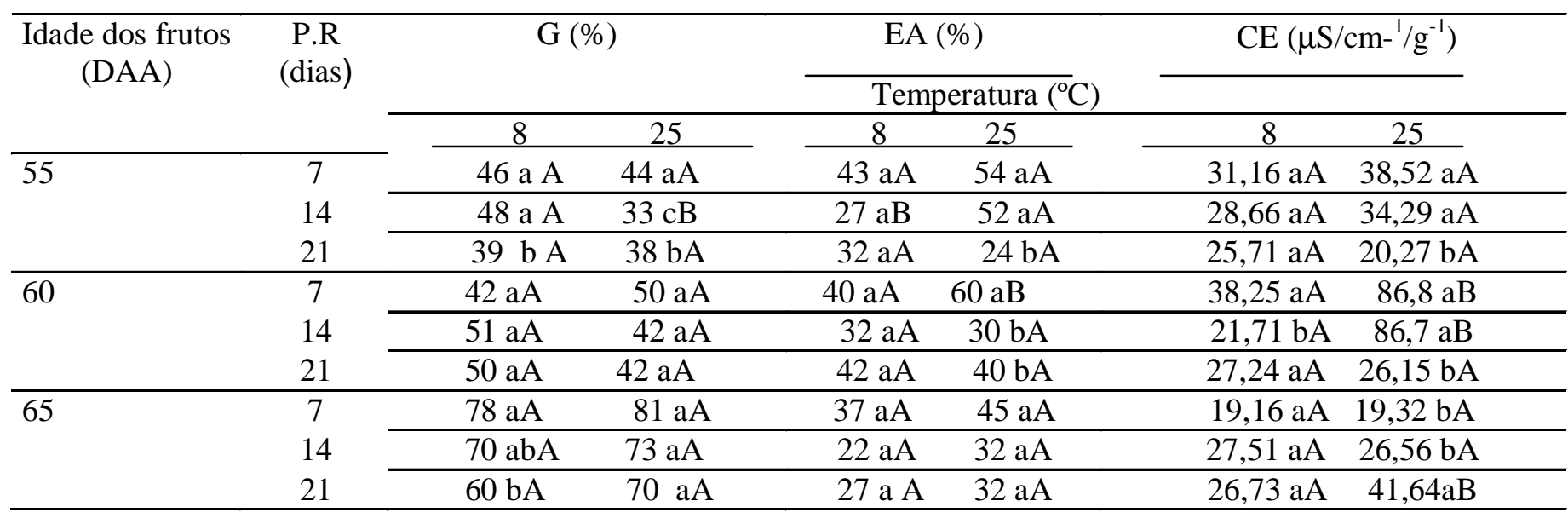

Na coluna, médias seguidas de letras minúsculas iguais não diferem pelo teste de Tukey ao nível de 5\% de probabilidade.

$\mathrm{Na}$ linha, médias seguidas de letras maiúsculas iguais não diferem pelo teste de Tukey ao nível de 5\% de probabilidade.

TABELA 3. Valores médios referentes ao teor de água (U), massa seca (MS), germinação (G), envelhecimento acelerado (EA) e condutividade elétrica (CE ) e tratamentos adicionais em sementes de maracujá amarelo em função da idade dos frutos (DAA), período de repouso (dias) e temperatura ambiente de repouso ( ${ }^{\circ} \mathrm{C}$ ).

\begin{tabular}{|c|c|c|c|c|c|}
\hline Tratamentos & $\mathrm{U}(\%)$ & $\mathrm{MS}(\mathrm{g})$ & $\mathrm{G}(\%)$ & $\mathrm{EA}(\%)$ & $\mathrm{CE}(\mu \mathrm{S} / \mathrm{cm} / \mathrm{g})$ \\
\hline $\mathrm{T}_{1}-55 \mathrm{DAA}(\mathrm{FSR})$ & $29,2 \mathrm{~b}$ & $0,98 \mathrm{a}$ & $51 \mathrm{~b}$ & $28 \mathrm{a}$ & $41,33 \mathrm{~b}$ \\
\hline $\mathrm{T}_{2} .55 \mathrm{DAA}, 7 \mathrm{PR}, 8^{\circ} \mathrm{AA}$ & $27,0 \mathrm{c}$ & $0,92 \mathrm{a}$ & $46 \mathrm{~b}$ & $43 \mathrm{a}$ & $31,16 \mathrm{~b}$ \\
\hline $\mathrm{T}_{3}, 55 \mathrm{DAA}, 7 \mathrm{PR}, 25^{\circ} \mathrm{AA}$ & $33,3 \mathrm{~b}$ & $0,79 \mathrm{a}$ & $44 \mathrm{~b}$ & $54 \mathrm{a}$ & $38,52 \mathrm{~b}$ \\
\hline $\mathrm{T}_{4-} 60 \mathrm{DAA}(\mathrm{FSR})$ & $19,8 \mathrm{c}$ & $0,96 \mathrm{a}$ & $74 \mathrm{a}$ & $27 \mathrm{a}$ & $38,54 \mathrm{~b}$ \\
\hline $\mathrm{T}_{5}, 60 \mathrm{DAA}, 7 \mathrm{PR}, 8^{\circ} \mathrm{AA}$ & $29,5 \mathrm{~b}$ & $1,00 \mathrm{a}$ & $42 \mathrm{~b}$ & $40 \mathrm{a}$ & $38,25 \mathrm{~b}$ \\
\hline $\mathrm{T}_{6}-60 \mathrm{DAA}, 7 \mathrm{PR}, 25^{\circ} \mathrm{AA}$ & $43,4 \mathrm{a}$ & $0,75 \mathrm{a}$ & $50 \mathrm{~b}$ & $60 \mathrm{a}$ & $86,70 \mathrm{a}$ \\
\hline $\mathrm{T}_{7-65 \mathrm{DAA}(\mathrm{FSR})}$ & $20,5 \mathrm{c}$ & $1,00 \mathrm{a}$ & $69 \mathrm{a}$ & $25 \mathrm{a}$ & $32,91 \mathrm{~b}$ \\
\hline $\mathrm{T}_{8}-65 \mathrm{DAA}, 7 \mathrm{PR}, 8^{\circ} \mathrm{AA}$ & $22,2 \mathrm{c}$ & $0,93 \mathrm{a}$ & $78 \mathrm{a}$ & $37 \mathrm{a}$ & $19,16 \mathrm{~b}$ \\
\hline $\mathrm{T}_{9}, 65 \mathrm{DAA}, 7 \mathrm{PR}, 25^{\circ} \mathrm{AA}$ & $21,7 \mathrm{c}$ & $0,92 \mathrm{a}$ & $81 \mathrm{a}$ & $45 \mathrm{a}$ & $19,32 \mathrm{~b}$ \\
\hline $\mathrm{T}_{10-} 55 \mathrm{DAA}, 14 \mathrm{PR}, 8^{\circ} \mathrm{AA}$ & $26,9 \mathrm{c}$ & $0,77 \mathrm{a}$ & $48 \mathrm{~b}$ & $27 \mathrm{a}$ & $28,66 \mathrm{~b}$ \\
\hline $\mathrm{T}_{11}$. 55 DAA, $14 \mathrm{PR}, 25^{\circ} \mathrm{AA}$ & $32,2 \mathrm{~b}$ & $1,09 \mathrm{a}$ & $33 \mathrm{~b}$ & $52 \mathrm{a}$ & $34,29 \mathrm{~b}$ \\
\hline $\mathrm{T}_{12}=60 \mathrm{DAA}, 14 \mathrm{PR}, 8^{\circ}$ AA & $21, \mathrm{c}$ & $0,98 \mathrm{a}$ & $51 \mathrm{~b}$ & $32 \mathrm{a}$ & $21,71 \mathrm{~b}$ \\
\hline $\mathrm{T}_{13}, 60 \mathrm{DAA}, 14 \mathrm{PR}, 25^{\circ} \mathrm{AA}$ & $44,4 \mathrm{a}$ & $0,71 \mathrm{a}$ & $42 \mathrm{~b}$ & $30 \mathrm{a}$ & $86,80 \mathrm{a}$ \\
\hline $\mathrm{T}_{14-}$ 65 DAA, $14 \mathrm{PR}, 8^{\circ} \mathrm{AA}$ & $31,2 \mathrm{~b}$ & $0,70 \mathrm{a}$ & $70 \mathrm{a}$ & $22 \mathrm{a}$ & $27,51 \mathrm{~b}$ \\
\hline $\mathrm{T}_{15}, 65 \mathrm{DAA}, 14 \mathrm{PR}, 25^{\circ} \mathrm{AA}$ & $22,2 \mathrm{c}$ & $1,01 \mathrm{a}$ & $73 \mathrm{a}$ & $32 \mathrm{a}$ & $26,56 \mathrm{~b}$ \\
\hline $\mathrm{T}_{16-}$ 55 DAA,21 PR, $8^{\circ} \mathrm{AA}$ & $31,7 \mathrm{~b}$ & $0,87 \mathrm{a}$ & $39 \mathrm{~b}$ & $32 \mathrm{a}$ & $25,71 \mathrm{~b}$ \\
\hline $\mathrm{T}_{17}$.55 DAA,21 PR, $25^{\circ} \mathrm{AA}$ & $22,5 \mathrm{c}$ & $1,22 \mathrm{a}$ & $38 \mathrm{~b}$ & $24 \mathrm{a}$ & $20,27 \mathrm{~b}$ \\
\hline $\mathrm{T}_{18}-60 \mathrm{DAA}, 21 \mathrm{PR}, 8^{\circ} \mathrm{AA}$ & $27,2 \mathrm{c}$ & $0,91 \mathrm{a}$ & $50 \mathrm{~b}$ & $42 \mathrm{a}$ & $27,24 \mathrm{~b}$ \\
\hline $\mathrm{T}_{19}$.60 DAA, $21 \mathrm{PR}, 25^{\circ} \mathrm{AA}$ & $26,2 \mathrm{c}$ & $1,02 \mathrm{a}$ & $42 \mathrm{~b}$ & $40 \mathrm{a}$ & $26,15 \mathrm{~b}$ \\
\hline $\mathrm{T}_{20}-65 \mathrm{DAA}, 21 \mathrm{PR}, 8^{\circ}$ AA & $22,2 \mathrm{c}$ & $0,84 \mathrm{a}$ & $60 \mathrm{a}$ & $27 \mathrm{a}$ & $26,73 \mathrm{~b}$ \\
\hline $\mathrm{T}_{21-} 65 \mathrm{DAA}, 21 \mathrm{PR}, 25^{\circ} \mathrm{AA}$ & $33,5 \mathrm{~b}$ & $0,87 \mathrm{a}$ & $70 \mathrm{a}$ & $32 \mathrm{a}$ & $41,64 \mathrm{~b}$ \\
\hline $\mathrm{CV}(\%)$ & 17 & 22 & 19 & 24 & 32 \\
\hline
\end{tabular}

FSR- frutos sem repouso, DAA - dias após a antese, PR - período de repouso, AA - ambiente de armazenamento.

Na coluna, médias seguidas de letras minúsculas iguais não diferem pelo teste de Scott Nott ao nível de 5\% de probabilidade. 
submetidos a repouso em ambiente natural, apresentaramse melhor quando comparado com o repouso em ambiente refrigerado. Dessa forma revelou que o repouso pós-colheita do fruto em ambiente natural, à exemplo do que acontece com outras espécies como melancia (Alvarenga et al., 1984), pepino (Barbedo et al., 1999), e mamão (Aroucha , 2004 e Balbinot, 2004) entre outras, proporcionou melhoria na qualidade das sementes.

O repouso dos frutos de maracujá doce em condições de refrigerador proporcionou maior porcentagem de sementes dormentes do que em ambiente natural, talvez por paralisação de algum processo fisiológico, resultando em menor porcentagem de germinação (Osipi, 2000). Todavia, a presente pesquisa mostrou que o ambiente de refrigerador não inibiu a germinação das sementes de maracujá amarelo.

Ao comparar a percentagem de germinação entre frutos em ponto de colheita comercial e frutos amadurecidos na planta próximos a sua queda, Osipi (2000) constatou ainda que para a extração e utilização imediata das sementes, o melhor foi deixar o fruto amadurecer na planta.

Estudando a influência da época de colheita e do repouso dos frutos de mamão na qualidade fisiológica das sementes, Aroucha (2004) concluiu que a época de colheita do fruto e o período de repouso contribuíram para um aumento significativo na germinação das sementes.

Maiores períodos de repouso dos frutos favoreceram a germinação de sementes de mamão (Carica papaya L.), avaliadas antes do armazenamento, conforme Balbinoti (2004) a germinação ficou abaixo de 50\%, quando houve repouso inferior a quatro dias; a percentagem de germinação aumentou significativamente, quando o período de repouso aumentou, ficando entre quatro e nove dias. No entanto, obteve-se o maior potencial germinativo quando o período de repouso dos frutos foi superior a nove dias. Ambos resultados corroboram os encontrados nesta investigação, pois observou-se um aumento significativo na germinação de sementes colhidas 65 dias após a antese, após sete dias de repouso dos frutos.

O repouso pós-colheita dos frutos mostrou-se benéfico quanto à germinação das sementes para frutos de até 35 dias de idade. A partir desta idade tal repouso não promoveu melhora na germinação das sementes, e chegou mesmo a causar decréscimo para as idades 40 e 45 dias. Um fato importante a salientar é que o repouso dos frutos propiciou a ocorrência de germinação das sementes em frutos novos, até os 20 dias de idade, enquanto que nestas mesmas idades, sem este repouso pós-colheita, não ocorreu a germinação das sementes não ocorreu (Barbedo et al., 1994).

Verifica-se, pelos resultados, que não houve aumento no vigor das sementes em função da idade do fruto, como também em relação ao período de armazenamento do fruto.Observou-se que o valor foi mais elevado aos $60 \mathrm{DAA}$, após sete dias de armazenamento dos frutos à temperatura de $25^{\circ} \mathrm{C}$. No entanto, aos 65 DAA, onde o potencial germinativo da semente foi elevado, houve decréscimo no vigor da semente oriundas de frutos armazenados nos dois ambientes, evidenciando que o potencial de vitalidade de uma semente não está somente relacionado com o seu poder germinativo (Tabela 2).

Quanto à massa seca, nos frutos com 65 dias, a massa seca das sementes extraídas de frutos mantidos a $25^{\circ} \mathrm{C}$ foi elevada (Tabela 1), porém nesta época quando as sementes foram expostas às condições do teste de envelhecimento acelerado apresentaram baixo percentual de germinação, tanto no ambiente refrigerado como no natural, mostrando que o alto valor da massa seca não coincidiu com o vigor das sementes aos 65 dias de idade do fruto. Pelos dados da Tabela 3, observa-se que vigor foi mais elevado aos 60 DAA, após sete dias de armazenamento dos frutos a $25^{\circ} \mathrm{C}$ (60\%), sendo que a massa seca para a mesma idade do fruto, período de repouso e temperatura foi inferior $(0,75 \mathrm{~g})$ no ambiente natural.

Segundo Carvalho e Nakagawa (2000), quando a semente atinge o máximo de peso de matéria seca, ela atinge o ponto de maturidade fisiológica, ou seja, a semente se apresenta com o máximo de seu vigor. No entanto, Ellis e Pieta Filho (1992), citados por Marcos Filho (2005) sugeriram que o máximo potencial fisiológico somente ocorreria após a maturidade fisiológica da semente, considerando que esse momento não coincide com o de máximo vigor; de acordo com estes autores, a semente está fisiologicamente madura somente quando alcança o máximo vigor.

O efeito do tempo de armazenamento dos frutos sobre a semente é mais acentuado nas primeiras idades. Em 
sementes com 55 dias de idade, o armazenamento dos frutos contribuiu para a germinação, principalmente nas sementes obtidas de frutos armazenados a $25^{\circ} \mathrm{C}$, por sete $(54 \%) \mathrm{e}$ quatorze dias (52\%). Quando se compara com semente de frutos mais velhos, nota-se diminuição do efeito do armazenamento, ou seja, com 65 dias de idade, sementes armazenadas por sete, 14 e 21 dias apresentaram menor média na germinação e não diferiram significativamente entre si nos dois ambientes.

Segundo Filgueira (1972), o armazenamento dos frutos é viável no início da maturação das sementes, quando precisam de tempo suficiente para completar o processo de maturação e alcançar máximo desenvolvimento. Esta afirmativa é contrária aos resultados encontrados no presente trabalho, pois a germinação foi mais elevada aos 65 DAA, ou seja, na idade mais avançada do fruto, o que implica supostamente em sementes maduras fisiologicamente.

Com as médias de vigor aos 55 DAA em ambos ambientes, não se pode afirmar que o repouso dos frutos propiciou a formação de plântulas vigorosas nas menores idades. Barbedo et al. (1994) verificaram, no entanto, que o armazenamento dos frutos contribuiu para a formação de plântulas vigorosas mesmo nas sementes oriundas de frutos mais jovens.

Pelo teste de condutividade elétrica, as sementes colhidas aos 55 DAA, provenientes de frutos armazenados à $25^{\circ} \mathrm{C}$ por 21 dias e aos $65 \mathrm{DAA}$ à 8 e $25^{\circ} \mathrm{C}$, por sete e 14 dias, apresentaram uma redução na concentração de liberação de exsudados (Tabela 2), indicando assim a integridade da membrana nos períodos de repouso citados.

Contrariamente as sementes de maracujá submetidas ao teste de condutividade elétrica, retiradas de frutos armazenados à $25^{\circ} \mathrm{C}$, por sete e 14 dias, aos $60 \mathrm{DAA}$, mostraram maior exsudação de elementos lixiviados, Este aumento nos valores de condutividade é um indicativo do decréscimo na germinação e no vigor das sementes e este decréscimo é diretamente proporcional ao aumento da concentração de eletrólitos liberados pelas sementes de diversas espécies (Marcos Filho et al., 1990).

Pereira e Dias (2000) ao avaliar a qualidade de sementes de maracujá amarelo submetidas a diferentes métodos para remoção de mucilagem verificaram que o ácido clorídrico $(\mathrm{HCl})$ 1:2 por uma hora afetou a qualidade das sementes, segundo os autores provavelmente, a utilização de ácido pode ter comprometido a integridade do tegumento das sementes, uma vez que os tratamentos que envolveram este processo foram os que apresentaram os maiores valores de lixiviação eletrolítica.

Segundo Bewley e Black (1994), a perda da integridade das membranas do tonoplasto e plasmalema das células inicia-se a partir da maturidade fisiológica das sementes, prejudicando a permeabilidade seletiva e diminuindo sua atuação como barreira de restrição à passagem de solutos. Este processo é intensificado com o passar do tempo e dependente das condições de armazenamento, diminuindo o vigor e a viabilidade das sementes.

Pode-se afirmar que o teste de condutividade elétrica, portanto fornece subsídios para evidenciar o efeito da época de colheita e do período de repouso dos frutos na qualidade fisiológica da semente de maracujá, visto que frutos colhidos aos 65 dias após a antese e armazenados por sete dias apresentaram um aumento significativo na germinação das sementes em ambos ambientes, sendo que as sementes colhidas destes frutos (65 DAA e sete dias) apresentaram menor atividade de elementos lixiviados, evidenciando assim o seu maior vigor. As sementes provenientes dos frutos com 65 dias de idade apresentaram valores significativos de massa seca (tabela 1), para quase todos o períodos de repouso em ambos ambientes, exceto para 14 dias de repouso do fruto a $8^{\circ} \mathrm{C}$, onde a massa seca diferiu significativamente e foi inferior ao ambiente natural $\left(25^{\circ} \mathrm{C}\right)$. Logo, isto pode ser um indicativo de que neste estádio de desenvolvimento do fruto (65 DAA), as sementes atingiram a maturidade fisiológica, tendo em vista que o máximo de massa seca coincidiu com o maior percentual de germinação (Tabela 2).

Frutos de maracujá amarelo com 35 dias de idade obtidos da florada de dezembro, conforme Almeida et al. (1988) apesar de mostrarem-se bem formados com características indicativas de maturidade e possíveis de serem relacionados com o desenvolvimento e maturação das sementes, apresentavam o suco amarelo claro. Os autores constataram ainda existir na semente de maracujá amarelo, uma seqüência do desenvolvimento e da coloração do tegumento variando, no processo de maturação, de branca 
a amarela, depois de marrom clara a completamente escura. No presente trabalho, com base nos três épocas de colheita (55, 60 e 65 DAA), a partir dos 55 dias de idade após a antese, o tegumento das sementes já apresentava coloração totalmente escura, no entanto os dados (Tabela 1 e 2) não mostravam um comportamento indicativo de maturidade fisiológica das sementes.

\section{CONCLUSÕES}

As sementes de maracujá amarelo provenientes de frutos extraídos aos 65 dias após a antese e armazenados por sete dias, tanto em ambiente refrigerado como em ambiente natural apresentam maior percentual germinativo;

Frutos colhidos aos 65 dias de idade após a antese e armazenados por sete dias às temperaturas de $8^{\circ} \mathrm{C}$ e $25^{\circ} \mathrm{C}$ apresentam também maior acúmulo de matéria seca.

\section{REFERÊNCIAS}

AROUCHA, E. M. M. Influência do estádio de maturação, da época de colheita e repouso dos frutos e do condicionamento na qualidade fisiológica de sementes de mamão (Carica papaya L.). 2004. 102f. Tese (Doutorado em Produção vegetal). Universidade Estadual do Norte Fluminense - UENF, Campos dos Goytacazes - Rj, 2004.

ALMEIDA, A P., NAKAGAWA, J., AMEIDA, R. M. Maturação de sementes de maracujá amarelo. Experimento I In: IX Congresso Brasileiro de Fruticultura, Campinas- SP, 1987, 1988.

ALVARENGA, E.M, SILVA, R.F, ARAÚJO, E.F., CARDOSO, A.A. Influência da idade e armazenamento pós-colheita dos frutos na qualidade de sementes de melancia. Horticultura Brasileira, Brasília, v.2, n.2, p.5-8. 1984.

ARAÚJO E.F, MANTOVANI E.C, SILVA R.F. Influência da idade e armazenamento dos frutos na qualidade de sementes de abóbora. Revista Brasileira de Sementes, Brasília, v.4,n.1,p. 7787, 1982.

BALBINOT, E. Importância do manejo dos frutos na secagem e armazenamento de sementes de mamão (Carica papaya L.). 2004. 86f. Dissertação (Mestrado em Produção vegetal). Universidade Estadual do Norte Fluminense - UENF, Campos dos Goytacazes -RJ. 2004.

BARBEDO C. J., BARBEDO, A. S. C., NAKAGAWA J., SATO, O. Efeito da idade e do repouso pós-colheita de frutos de pepino na semente armazenada. Pesquisa Agropecuária Brasileira, Brasília, v. 34, n.5, p.839-847, 1999.
BRASIL. Ministério da Agricultura e Reforma Agrária. Regras para análise de sementes. Brasília: SNDA/DNDV/CLAV, 365p. 1992

BARBEDO, C.J., NAKAGAWA, J., BARBEDO, A.S.C., ZANIN, A.C.W. Influência da idade e do período de repouso pós-colheita de frutos de pepino cv. Rubi na qualidade fisiológica de sementes. Horticultura Brasileira, v.12, n.2, p.118-124, 1994.

BARBEDO, C.J.,COELHO, A.S., ZANIN, A.C.W., NAKAGAWA, J. Influência da idade do fruto na qualidade de sementes de pepino. Horticultura brasileira, v.11, n.1, p.18-21, 1993.

BEWLEY, J. D., BLACK M. Seeds: Physiology of development and germination. New York: Plenum Press, 1994. 445 p.

CARVALHO, A. .J. C., MARTINS D.P, MONNERAT, P. H., BERNADO, S. Adubação nitrogenada e irrigação do maracujazeiro-amarelo. I-Produtividade e qualidade dos frutos. Pesquisa Agropecuária Brasileira. Brasília, v. 35, n. 6, p. 1101$1108,2000$.

CARVALHO, N.M.; NAKAGAWA, J. Sementes: ciência, tecnologia e produção. 4. ed. Jaboticabal: FUNEP, 588 p. 2000.

COPELAND, L.. O., MCDONALD, M.B. Principles of seed science and technology. New York: Macmillan Publishing Company, 369p, 1985.

FILGUEIRA, F.A.R. Manual de olericultura: cultura e comercialização das hortaliças. São Paulo: Agr. Ceres, 1972. 451p.

KAYS, S.J. Postharvest Physiology of Perishable Plant Products, Athens: AVI, 532 p. Exon Press. 1997.

MANTOVANI, E.C, SILVA, R.F, CASALI V.W.D, CONDE A.R. Desenvolvimento e maturação fisiológica de sementes de pimentão (Capsicum annuum L.). Revista Ceres, Viçosa, v.27, n. 152, p. 356-368, 1980.

MANLY, B.F.J. (1990) Multivariate Statistical methods: A primer. Great Britain: Chapman and Hall, 159 p, 1990.

MARCOS FILHO, J. Fisiologia de sementes de plantas cultivadas. Piracicaba, FEALQ, 495p. 2005.

MARCOS FILHO, J.; SILVA, W.R.; NOVEMBRE, A.C.; CHAMA, H.C.P.C. Estudo comparativo de métodos para avaliação da qualidade fisiológica de sementes de soja, com ênfase ao teste de condutividade elétrica. Pesquisa Agropecuária Brasileira, Brasília, v.25, n.12, p. 1805-1815, 1990.

OSIPI, E. A. F. Efeito da temperatura, da maturação do fruto e do armazenamento na qualidade fisiológica de sementes de maracujá doce (Passiflora alata Dryander). 2000, 98f. Tese (Doutorado em Produção Vegetal). Universidade Estadual Paulista Julio de Mesquita. Botucatu. 2000. 
PEREIRA, K.J.C.; DIAS, D.C.F.S. Germinação e vigor de sementes de maracujá-amarelo (passiflora edulis sims. f. flavicarpa deg.) submetidas a diferentes métodos de remoção de mucilagem. Revista Brasileira de Sementes, vol. 22, n. 1, p.288-291, 2000.

RUGGIERO, C. Implantação da cultura e propagação. In: Ruggiero, C. (ed). Cultura do maracujazeiro. Ribeirão Preto, Legis Summa, p. 40-57, 1987.

SAADIAH, A.S.H., JUNAIDAH, B. Development of cucumber seed from flowering to maturity. Mardi Research Bulletin, v.14, n.1, p.47-51, 1986.
SILVA, M. G, AROUCHA, E. M.M., OLIVEIRA, J. G., CORREAA, S. F., FILHO, M. B., SILVA, R. F. DA, PEREIRA M. G., VARGAS, H. Influência da emissão de etileno na qualidade fisiológica de sementes de mamão (Carica papaya L.). In: II reunião de pesquisa do frutimamão, Campos dos Goytacazes, p.255-260, 2004.

KAYS, S.J. Postharvest Physiology of Perishable Plant Products. Athens: Exon Press AVI, 1997. 532p.

WUTHIPONGPRASERT, S., ANDRADE,A. P. DE, XU,Y. .J, BHATTI, M.H. Effect of seed maturing process and seed extraction process on germinability of cucumber seeds. Report on Experiments in Vegetable Seed production Course, Tsukuba, p. 203-210, 1985. 